\title{
Frequency of tuberculous and non-tuberculous mycobacteria in HIV infected patients from Bogota, Colombia Martha I Murcia-Aranguren ${ }^{1}$, Jorge E Gómez-Marin*2,3, Fernando S Alvarado3, José G Bustillo4, Ellen de Mendivelson4, Bertha Gómez5, Clara I León 6 , William A Triana7, Erwing A Vargas7 and Edgar Rodríguez7
}

Address: ${ }^{1}$ Departamento de Microbiologia, Facultad de Medicina-Universidad Nacional de Colombia, Bogota, Colombia, ${ }^{2}$ Centro de Investigaciones Biomedicas, Facultad de Ciencias de la Salud, Programa de Medicina, Universidad del Quindio, Armenia, Colombia, 3Unidad de Infectologia, Departamento de Medicina Interna, Facultad de Medicina-Universidad Nacional de Colombia, Bogota, Colombia, 4Departamento de Medicina Interna, Hospital Simón Bolívar, Bogota, 5Programa VIH/SIDA, Instituto de Seguros Sociales, CAB Chapinero, Bogota, Colombia, ${ }^{6}$ Grupo de Micobacterias, Instituto Nacional de Salud, Bogota, Colombia and 7Estudiantes de Medicina, Facultad de Medicina, Universidad Nacional de Colombia, Bogota, Colombia Armenia, Colombia

E-mail: Martha I Murcia-Aranguren - mimurcia@usa.net; Jorge E Gómez-Marin* - jegomezmarin@hotmail.com; Fernando S Alvarado - falvarado@cfl.rr.com; José G Bustillo - jbustill@ hotmail.com; Ellen de Mendivelson - hospitalsimonbolivar@yahoo.com; Bertha Gómez - berthaiss@latinmail.com; Clara I León - cleon@ hemagogus.ins.gov.co; William A Triana - watrianr@hotmail.com; Erwing A Vargas - vsa79@latinmail.com; Edgar Rodríguez - e_rodriguez_beltran@altavista.com ${ }^{*}$ Corresponding author

\begin{abstract}
Background: The prevalence of infections by Mycobacterium tuberculosis and non-tuberculous Mycobacterium species in the HIV-infected patient population in Colombia was uncertain despite some pilot studies. We determined the frequency of isolation of Mycobacterium tuberculosis and of non-tuberculous Mycobacterium species in diverse body fluids of HIV-infected patients in Bogota, Colombia.
\end{abstract}

Methods: Patients who attended the three major HIVIAIDS healthcare centres in Bogota were prospectively studied over a six month period. A total of 286 patients were enrolled, $20 \%$ of them were hospitalized at some point during the study. Sixty four percent $(64 \%)$ were classified as stage C, $25 \%$ as stage $B$, and II\% as stage $A$ (CDC staging system, 1993). A total of I,622 clinical samples (mostly paired samples of blood, sputum, stool, and urine) were processed for acid-fast bacilli (AFB) stain and culture.

Results: Overall 43 of I,622 cultures $(2.6 \%)$ were positive for mycobacteria. Twenty-two sputum samples were positive. Four patients were diagnosed with M. tuberculosis (I.4\%). All isolates of $M$. tuberculosis were sensitive to common anti-tuberculous drugs. M. avium was isolated in thirteen patients (4.5\%), but only in three of them the cultures originated from blood. The other isolates were obtained from stool, urine or sputum samples. In three cases, direct AFB smears of blood were positive. Two patients presented simultaneously with M. tuberculosis and M. avium.

Conclusions: Non-tuberculous Mycobacterium infections are frequent in HIV infected patients in Bogota. The diagnostic sensitivity for infection with tuberculous and non-tuberculous mycobacteria can be increased when diverse body fluids are processed from each patient. 


\section{Background}

Mycobacterium infections are frequent opportunistic pathogens associated with the acquired immunodeficiency syndrome (AIDS). Its relative virulence and potential for person-to-person transmission distinguishes Mycobacterium tuberculosis. Persons infected with the human immunodeficiency virus (HIV) are particularly susceptible to tuberculosis, either by the reactivation of latent infection or by a primary infection with rapid progression to active disease [1-4]. The annual incidence rate of tuberculosis in Colombia during 1998 was 19.6 per 100,000 persons [5], but rates 1,00o-fold higher have been reported in some HIV-seropositive populations [6-14]. In addition, disseminated infections with Mycobacterium avium complex are increasingly common in advanced human immunodeficiency virus (HIV) disease and cause substantial morbidity [15,16]. Persons with HIV infection and CD4 lymphocyte counts less than 100 cells $/ \mathrm{mm}^{3}$ have a probability of $10 \%$ to $20 \%$ per year of developing $M$. avium complex disease or bacteremia $[17,18]$. Bacteremia involving $M$. avium complex produces a wide array of clinical signs and symptoms, including wasting, fever, and night sweats, and is associated with decreased survival [17-20]. The recovery of mycobacteria in blood cultures can help to discover bacteremia that frequently goes unrecognized. We undertook a prospective survey in three AIDS health care units in Bogota, Colombia, in order to determine the prevalence of Mycobacterium species in HIV-infected patients and to evaluate the diagnostic value of different types of body fluids to detect the presence of mycobacteria.

\section{Methods}

\section{Patients and study design}

This study was a multicentric prospective study of the frequency of Mycobacterium infections in persons infected with HIV. The study was conducted in three major AIDS health care programs of Bogota ("Hospital Universitario San Juan de Dios", "Hospital Regional Simon Bolívar" and "Centro Atención Básica Chapinero del Seguro Social"). From October 1999 to March 2000, a total of 289 HIV-seropositive patients were recruited. Most of the participants met the definition of AIDS, or were in clinical stage C (CDC, 1993). The institutional review board at each site approved the study, and each participant gave written informed consent.

\section{Specimen collection and culture media}

For all patients blood, urine, stool and sputum samples were collected. In brief, 5 to $8 \mathrm{~mL}$ of blood was obtained in previously labeled Vacutainer ${ }^{\mathrm{TM}}$ tubes containing 1.7 $\mathrm{mL}$ of heparin as anticoagulant. All patients attempts were made to collect two paired blood cultures samples ( $\mathrm{n}=648), 2$ urine cultures $(\mathrm{n}=497), 2$ stool cultures ( $\mathrm{n}$ $=374)$ and 2 sputum samples $(\mathrm{n}=101)$. In one patient a sample of ascitic fluid, and in other case cerebrospinal fluid (CSF) were obtained. Bacteriologic methods were used as previously described [21,22]. Briefly, blood samples were centrifuged $15 \mathrm{~min}$ at 2,00o $\mathrm{g}$ and leukocytes recovered by standard methods with Ficoll-Hypaque (Pharmacia Fine Chemicals, Piscataway, NJ) and then mixed with a lysing solution that contained $0.45 \%$ sodium deoxycholate. After manual mixing, tubes were centrifuged at $3,500 \mathrm{~g}$ for 30 minutes in a refrigerated centrifuge at 4,000 $\mathrm{g}$ and the supernatant was discarded. The pellet was resuspended, and $0.2 \%$ bovine albumin was added to yield a final volume of $2.5 \mathrm{~mL}$.

One gr of stool samples was placed in $5 \mathrm{ml}$ of albumin Dubos media and mixed in Vortex ${ }^{\mathrm{TM}}$ for $2 \mathrm{~min}$, then incubated at room temperature overnight. Afterwards, equal volumes of a solution of $2 \% \mathrm{NaOH}$ were mixed in Vortex $^{\mathrm{TM}}$ for $2 \mathrm{~min}$ and incubated at room temperature in continuos mixing for $15 \mathrm{~min}$. Distilled water was added to complete $50 \mathrm{ml}$ and the mixture was centrifuged at $6,000 \mathrm{~g}$ for $30 \mathrm{~min}$. One drop of phenol red was added to the pellet and then neutralized with 2 drops of $\mathrm{HCl} 2 \mathrm{~N}$. The pellet was resuspended in $2 \mathrm{ml}$ of saline solution, mixed and finally $0.2 \mathrm{ml}$ used for culture.

Urine samples were mixed in a ratio of 3:1 with a solution of $20 \% \mathrm{Na}_{3} \mathrm{PO}_{4} \cdot 12 \mathrm{H}_{2} \mathrm{O}$. The mixture was incubated at room temperature for $2 \mathrm{~h}$ and then centrifuged at 6,000 $\mathrm{g}$ for $30 \mathrm{~min}$. The pellet was used for culture after being decontaminated by Ogawa-Kudoh method. Briefly, sterile slabs were placed in a solution of $4 \% \mathrm{NaOH}$ during 1 or $2 \mathrm{~min}$ and then used to culture samples.

Sputum was mixed in equal volume with a solution of $4 \%$ $\mathrm{Na}_{3} \mathrm{PO}_{4} \cdot 12 \mathrm{H}_{2} \mathrm{O}$, incubated at room temperature during 2 $\mathrm{h}$ and centrifuged at $6,000 \mathrm{~g}$ for $30 \mathrm{~min}$. The pellet was decontaminated by the Ogawa-Kudoh method, as described above, and used for culture. The same procedure was used for the ascitic fluid and CSF samples.

All samples were placed in 2 tubes with a biphasic medium: a solid phase Ogawa-Kudoh with iron citrate and a liquid phase of Sauton Twen albumin modified medium and 2 tubes with Stonebrink-Giraldo medium. Readings were made after day 6 and at 2, 4, 6, 8, 12 and 16 week. A positive culture was identified following the criteria of the Centers for Prevention and Disease Control (CDC) [22]. Resistance assay was applied at all Mycobacterium tuberculosis isolates using the proportion method for streptomycin $(\mathrm{S})$, isoniazide $(\mathrm{H})$, thioacetazone $(\mathrm{Tb})$, ethambutol (E) and rifampicin (R).

All samples were stained and examined for AFB after centrifugation. 
Figure 1. Frequency of clinical symptoms

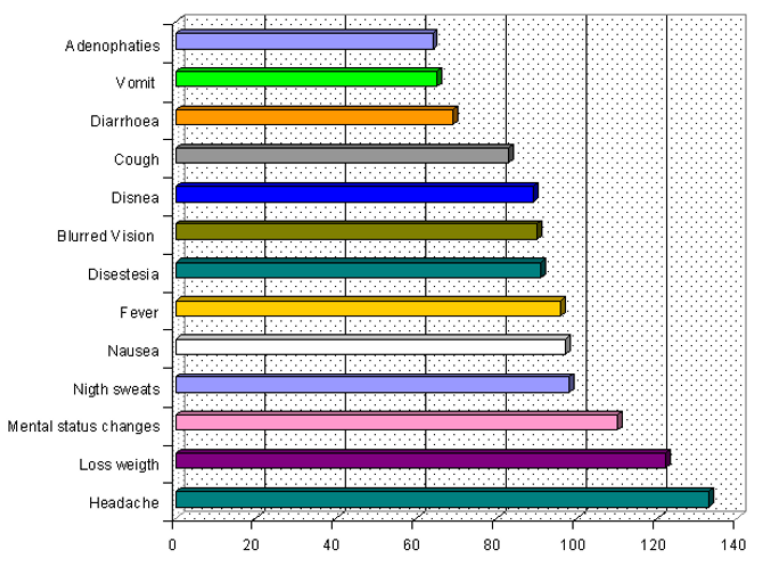

Figure I

Frequency of clinical symptoms

\section{Statistical analysis}

Statistical significance for comparison of rates was determined by an exact test when sample sizes were insufficient and by an asymptotic test when sizes were sufficient. All tests were two-sided, and a $\mathrm{P}$ value of 0.05 was considered significant. Exact 95\% confidence intervals (CI) were calculated for rates by assuming the numerator to be a Poisson variable [23] and for rate ratios using a modified binomial model [24]. Adjusted rate ratios for comparisons among groups defined by demographic variables were calculated by using a MantelHaenszel type estimator for incidence-rate data with approximate $95 \%$ confidence limits based on the tests [23].

\section{Results}

\section{Demographic characteristics}

In total, 286 patients were studied, 251 (87.8\%) were men, and 35 (12.2\%) were women. The men:women ratio was $7: 1$. The age range was 3 to 78 years with a median of 35 years (Table 1$)$. Ten patients (3\%) were from "Hospital San Juan de Dios"; one-hundred thirty nine patients (49\%) were from "Hospital Simón Bolívar" and one hundred thirty seven patients (48\%) were from the "Instituto de Seguro Social". Fifty-eight patients were hospitalized at the time of enrollment (20\%), and two hundred twenty eight patients $(80 \%)$ were enrolled at an outpatient clinic. One hundred ninety five patients (68.5\%) were in treatment with antiretroviral medication. Sexual preferences were informed in 269 (94\%) patients as follows: in males, ninety (33.4\%) were homosexual, eighty-six (31.9\%) were bisexual and sixty-one $(22.7 \%)$ were heterosexual. Of the women, twenty-nine (90.6\%) were heterosexual and three (9.4\%) were bisexual. CDC staging in these patients is shown in Table 1. Viral load was obtained in 180 patients and results varied in a range between less than 50 and 13 millions copies $/ \mathrm{mL}$. The median of viral load was 23,420 copies $/ \mathrm{mL}$.

The symptoms most frequently complaint of at the time of initial enrollment were headaches (48\%), loss of weight (43\%), and mental status changes (38\%). The frequency of each symptom is showed in Figure 1. 29\% patients complaint of respiratory symptoms. 13\% patients had a history of diagnosis of tuberculosis, and $12 \%$ gave a history of previous treatment with antituberculous drugs.

Table I: Demographic characteristics of patients

\begin{tabular}{|c|c|c|}
\hline Distribution by center & $\mathbf{n}$ & $\%$ \\
\hline Hospital San Juan de Dios & 10 & \\
\hline Male & 9 & 90 \\
\hline Women & I & 10 \\
\hline Hospital Simon Bolívar & 139 & \\
\hline Male & 128 & 95 \\
\hline Women & 21 & 15 \\
\hline Seguro Social & 137 & \\
\hline Male & 124 & 90 \\
\hline Women & 13 & 10 \\
\hline \multicolumn{3}{|l|}{ Age groups } \\
\hline $0-15$ & $\mathbf{I}$ & 0.35 \\
\hline $16-25$ & 38 & 13.3 \\
\hline $26-45$ & 211 & 73.8 \\
\hline $46-65$ & 35 & 12.2 \\
\hline $66-78$ & I & 0.35 \\
\hline \multicolumn{3}{|l|}{ I993 CDC stages } \\
\hline $\mathrm{A}$ & 31 & I I \\
\hline B & 69 & 24 \\
\hline C & 186 & 65 \\
\hline
\end{tabular}

\section{Mycobacterium infection}

Overall, sixteen of 286 patients (5.6\%) were positive for any Mycobacterium species by acid fast staining or culture of any of their samples. In these sixteen cases, fifteen (94\%) were positive by culture, and one patient was detected only by acid fast bacilli staining (6\%). Fourteen patients $(87.5 \%)$ were men and two (12.5\%) were women. M. tuberculosis was identified in four cases $(1.4 \%)$. M. avium was isolated in thirteen patients (4.2\%). Two patients presented simultaneous infection by M. tuberculosis and M. avium.

Tuberculosis was diagnosed in its pulmonary form in two cases, and in another two patients as extrapulmonary. In the patients with pulmonary tuberculosis, the AFB smear of the sputum was positive in one case, and in another 
Table 2: Staining and culture of $M$. tuberculosis

\begin{tabular}{|c|c|c|c|c|c|}
\hline Patient & Clinical form & Type of Sample & Number of Samples & AFB SMEAR POSITIVE & CULTURE POSITIVE \\
\hline \multirow[t]{3}{*}{1} & Disseminated & Sputum & 2 & 2 & 2 \\
\hline & & Urine & 2 & 0 & 2 \\
\hline & & Ascitic fluid & 1 & 1 & 1 \\
\hline \multirow[t]{2}{*}{$2^{*}$} & Pulmonary & Sputum & 2 & 2 & 2 \\
\hline & & Stool & 2 & 2 & 2 \\
\hline \multirow[t]{2}{*}{3} & Pulmonary & Sputum & 2 & 0 & 2 \\
\hline & & Stool & 2 & 1 & 2 \\
\hline \multirow[t]{2}{*}{4} & Gastrointestinal & Stool & 2 & 2 & 2 \\
\hline & & TOTAL & 15 & 10 & 15 \\
\hline
\end{tabular}

$2^{*}$ This patient also presented positive culture for M. avium

Table 3: Staining and culture of $M$. avium in blood samples

\begin{tabular}{|c|c|c|c|c|c|c|}
\hline \multirow[b]{2}{*}{ Patient } & \multirow[b]{2}{*}{ Sample } & \multirow[b]{2}{*}{ Number of Samples } & \multicolumn{2}{|c|}{ AFB smear } & \multicolumn{2}{|c|}{ Culture } \\
\hline & & & Positive & Negative & Positive & Negative \\
\hline $\mathbf{I}$ & blood & 2 & I & I & 2 & 0 \\
\hline 2 & blood & 2 & 1 & I & 2 & 0 \\
\hline 3 & blood & 2 & I & I & 2 & 0 \\
\hline \multirow[t]{4}{*}{$3^{*}$} & blood & 2 & 0 & 2 & 2 & 0 \\
\hline & urine & 2 & 1 & I & 2 & 0 \\
\hline & stool & 2 & 2 & 0 & 2 & 0 \\
\hline & TOTAL & 12 & 6 & 6 & 12 & $\mathbf{0}$ \\
\hline
\end{tabular}

3* Sample after one month of follow. This patient had past history of tuberculosis

case the AFB smear was positive in his stool sample. Culture of stool samples was positive in both cases of pulmonary and in one case of extrapulmonary tuberculosis. $M$. tuberculosis was detected in different samples of body fluids as well: in sputum, urine, stool samples, and in ascitic fluid (Table 2). All isolates of $M$. tuberculosis were sensitive to the drugs assayed: streptomycin $(S)$, isoniazide $(\mathrm{H})$, thioacetazone (Th), ethambutol (E) and rifampicin (R).

The only species identified as non-tuberculous mycobacteria was $M$. avium which was detected in 13 patients (4.2\%). Two patients had coinfection by $M$. tuberculosis and $M$. avium in their sputum culture. One patient was positive only for acid fast bacilli staining in two stool samples but no growth was observed in culture tubes after 16 weeks of incubation. Interestingly, in three patients the direct AFB staining in blood was positive, and $M$. avium was later identified in these blood cultures (Table 3). M. avium was also detected in other clinical samples: urine, stool and sputum (Table 4).
The percent of positive AFB smears and cultures was greater in samples of sputum followed by the samples of stool (Table 5). Samples of urine and stool were valuable to identify most of patients with a $M$. avium infection, only three patients infected by $M$. avium were identified solely by blood cultures (Table 6 and 7 ).

\section{Association between Mycobacterium avium infection and clinical data}

The following factors (Table 6) were significantly associated with a culture positive for $M$. avium infections: death during time of follow up (odds ratio [OR], 9.7 [95\% CI, 2.8-32]), loss of weight (OR, 8 [95\% CI, 1.6-54]), and diarrhea (OR, 3.9 [95\% CI, 1.1-14]). The mean time of survival during the study was significantly reduced inpatients infected with Mycobacterium avium compared to the ones not infected (154 \pm 44 versus $170 \pm 37$ days, $p$ $=0.01$ ). There were no statistically significant differences in age, sex, clinical stage, CD4 cell count, viral load, use of antiretrovirals drugs or time of diagnosis since HIV infection between patients with or without myco- 
Table 4: Staining and culture of $M$. avium in clinical samples other than blood

\begin{tabular}{|c|c|c|c|c|c|c|}
\hline \multirow[b]{2}{*}{ PATIENT } & \multirow[b]{2}{*}{ SAMPLE } & \multirow[b]{2}{*}{ Number of Samples } & \multicolumn{2}{|c|}{ AFB Smear } & \multicolumn{2}{|c|}{ Culture } \\
\hline & & & POS & NEG & POS & NEG \\
\hline 1 & Stool & 2 & 0 & 2 & 1 & I \\
\hline 2 & Stool & 2 & 0 & 2 & 1 & 1 \\
\hline 3 & Stool & 2 & 2 & 0 & 2 & 0 \\
\hline 4 & Urine & 2 & 0 & 2 & 2 & 0 \\
\hline 5 & Urine & 2 & 0 & 2 & 2 & 0 \\
\hline 6 & Urine & 2 & 0 & 2 & 1 & I \\
\hline 7 & Urine & 2 & 0 & 2 & 2 & 0 \\
\hline $8^{*}$ & Sputum & 2 & 2 & 0 & 2 & 0 \\
\hline \multirow[t]{2}{*}{$9^{*}$} & Sputum & 2 & 2 & 0 & 1 & 0 \\
\hline & TOTAL & 18 & 6 & 12 & 14 & 3 \\
\hline
\end{tabular}

$8^{*}$ Patient with past history of TB $9 *$ Patient with simultaneous finding of $M$. tuberculosis

Table 5: Positivity for Mycobacterium infection and type of sample $(n=1622)$

\begin{tabular}{|c|c|c|c|c|c|c|c|c|}
\hline \multirow[t]{3}{*}{ SAMPLE } & \multicolumn{4}{|c|}{ CULTURE } & \multicolumn{4}{|c|}{ AFB Smear } \\
\hline & POSITIVE & & NEGATIVE & & POSITIVE & & NEGATIVE & \\
\hline & $\mathrm{N}$ & $\%$ & $\mathrm{n}$ & $\%$ & $\mathrm{n}$ & $\%$ & $\mathrm{n}$ & $\%$ \\
\hline Blood & 8 & 1.2 & 640 & 98.8 & 3 & 0.5 & 645 & 99.5 \\
\hline Stool & 12 & 3.2 & 362 & 96.8 & 11 & 3 & 363 & 97 \\
\hline Sputum & 8 & 8 & 93 & 92 & 6 & 6 & 93 & 94 \\
\hline CSF & 0 & 0 & 1 & 100 & 0 & 0 & 1 & 100 \\
\hline Ascitic fluid & 1 & 100 & 0 & 0 & 1 & 100 & 0 & 0 \\
\hline TOTAL & 40 & 2.5 & 1582 & 97.5 & 22 & 1.3 & 1600 & 98.7 \\
\hline
\end{tabular}

Table 6: Clinical findings associated with Mycobacterium avium infection

\begin{tabular}{lccc}
\hline \multicolumn{1}{c}{ Clinical findings } & Odds Risk & CI 95\% & P \\
\hline & & & \\
Death* & 9.7 & $(2.8-32)$ & $\mathbf{0 . 0 0 0 5}$ \\
Loss of weight* & 8.0 & $(1.6-54)$ & $\mathbf{0 . 0 0 4}$ \\
Diarrhea* & 4.5 & $(1.1-14)$ & $\mathbf{0 . 0 1 7}$ \\
Hemoptysis & 3.6 & $(0-16)$ & 0.1 \\
Cough & 2.1 & $(0.6-6.9)$ & 0.2 \\
Hospitalization & 2.5 & $(0.7-8.3)$ & 0.1 \\
History of past TB & 2.1 & $(0.4-7.9)$ & 0.2 \\
Dyspnea & 1.9 & $(0.5-6.8)$ & 0.2 \\
Fever & 1.7 & $(0.5-5.5)$ & 0.3 \\
Lymphadenopaties & 1.0 & $(0.2-5.7)$ & 1.0 \\
& & & \\
\hline
\end{tabular}

* Statistically significant associations $p<0.05$ bacterial infection (Table 7). However, there were no patients with $M$. avium infections in clinical stage A or with a CD4 cell count higher than 500 cells $/ \mathrm{mm}^{3}$ (Tables 8 and 9).

\section{Discussion}

Our study was a prospective study in HIV infected patients in whom an indiscriminate search Mycobacterium infection was done. Clinical suspicion of tuberculosis existed previous to enrollment only in the two patients with pulmonary Mycobacterium tuberculosis infection but not in the other two patients with extrapulmonary tuberculosis.

Most of Mycobacterium species isolated were M. avium

The frequency that we found was lower than that of previously reported studies for Mycobacterium in HIV in- 
Table 7: Demographic and clinical characteristics in patients with and without Mycobacterium avium infection

\begin{tabular}{|c|c|c|c|c|c|c|c|}
\hline & \multicolumn{2}{|c|}{$\begin{array}{l}\text { Patients with } M . \text { avium infec- } \\
\text { tion }\end{array}$} & \multirow[t]{2}{*}{$\begin{array}{l}\text { Ist and } 3^{\text {rd }} \text { quar- } \\
\text { tile }\end{array}$} & \multicolumn{2}{|c|}{$\begin{array}{l}\text { Patients without M. avium } \\
\text { infection }\end{array}$} & \multirow[t]{2}{*}{$\begin{array}{l}\text { Ist and } 3^{\text {rd }} \\
\text { quartile }\end{array}$} & \multirow[t]{2}{*}{$\mathbf{p}$} \\
\hline & $\begin{array}{l}\mathbf{N} \text { (patients } \\
\text { with data) }\end{array}$ & $\begin{array}{l}\text { Median or } \\
\text { percent }\end{array}$ & & $\begin{array}{l}\mathbf{N} \text { (patients } \\
\text { with data) }\end{array}$ & $\begin{array}{l}\text { Median or } \\
\text { percent }\end{array}$ & & \\
\hline Age & 13 & 33 & [23-39] & 273 & 35 & [29-40] & 0.2 \\
\hline Sex male & 13 & $92 \%$ & & 273 & $88 \%$ & & 0.5 \\
\hline CD4 cell counts & 13 & 115 & [30-223] & 219 & 164 & [60-325] & 0.2 \\
\hline Viral load & 8 & 52,000 & {$[5,967-227,941]$} & 172 & 23,000 & {$[746-147,131]$} & 0.5 \\
\hline Use of antiretrovirals & 13 & $61.5 \%$ & & 272 & $68.7 \%$ & & 0.8 \\
\hline $\begin{array}{l}\text { Time with antiretroviral } \\
\text { treatment (months) }\end{array}$ & 10 & 29 & [18-60] & 175 & 22 & {$[12-32]$} & 0.2 \\
\hline $\begin{array}{l}\text { Time with diagnosis of } \\
\text { VIH infection (months) }\end{array}$ & 10 & 18.5 & [15-28] & 175 & 27 & [13-50] & 0.2 \\
\hline
\end{tabular}

Table 8: Clinical stage of HIV infection and positivity for Mycobacterium infection

\begin{tabular}{ccc}
\hline CLINICAL STAGE & POSITIVE & TOTAL \\
\hline A & $0(0 \%)$ & $0 / 31(0 \%)$ \\
B & $3(19 \%)$ & $3 / 69(4.4 \%)$ \\
C & $13(81 \%)$ & $13 / 186(7 \%)$ \\
TOTAL & $16(100 \%)$ & $16 / 286$ \\
& & $(5.6 \%)$ \\
\hline
\end{tabular}

Table 9: Relation between CD4 cell count and infection with Mycobacterium

\begin{tabular}{ccc}
\hline CD4+ cells & POSITIVES & TOTAL \\
\hline$\left(>500 / \mathrm{mm}^{3}\right)$ & $0(0 \%)$ & $0 / 24(0 \%)$ \\
$\left(200-499 / \mathrm{mm}^{3}\right)$ & $6(37 \%)$ & $6 / 83(7.2 \%)$ \\
$\left(<200 / \mathrm{mm}^{3}\right)$ & $8(50 \%)$ & $8 / 126(6.3 \%)$ \\
ND & $2(13 \%)$ & $2 / 53(3.7 \%)$ \\
TOTAL & $16(100 \%)$ & $16 / 262(6.1 \%)$
\end{tabular}

fected patients in Colombia. A previous study at the "Hospital San Juan de Dios" in 1996 performed in 92 HIV infected patients found a prevalence of $8 \%$ for $M$. tuberculosis infection [25]. In another study in 101 patients in Cali, Colombia, the prevalence was only $2 \%$ [26]. In the present study it was $1.4 \%$.
The prevalence of non-tuberculous Mycobacterium species in Cali was 5\% [27], and in the current study it was $4 \%$. The lower prevalence of $M$. tuberculosis, can be related to the introduction of highly active antiretroviral therapy (HAART) that was practically absent in the previous study in Bogota in 1996 but that was being used to treat $68 \%$ of the patients in the current study. Our results are also different to the ones reported in a General Hospital, AIDS reference center, in Rio de Janeiro, Brazil [28] where mycobacteria were recovered from $20.6 \%$ (313 of 1,517) of all patients, and M. tuberculosis was identified in $94.2 \%$ (295/313), and non-tuberculous mycobacteria in $5.8 \%(18 / 313)$. Our results suggest that when antiretroviral therapy is introduced the relative frequency of $M$. tuberculosis infections is reduced and the one of $M$. avium infections increases [28].

We found that Mycobacterium avium infection was related to symptomatic diarrhea and greater mortality as has been reported previously [29]. Our study shows that frequency of isolation of $M$. avium was greater in urine and stool samples. This emphasizes the need to take multiple body fluid samples in order to enhance the opportunity of isolation increasing the microbiologic diagnostic sensitivity. Interestingly, we found that blood AFB smears can be useful to rapidly confirm a clinical diagnosis of disseminated Mycobacterium avium infection.

In the present study there were no resistant strains of $M$. tuberculosis found. In a previous survey in Colombia it was found that $M$. tuberculosis isolates among new cases in patients without HIV infection showed resistance in $9.5 \%$ (4 of 42$)$ [30]. 


\section{Conclusions}

Our study found that $5 \%$ of HIV infected patients in Bogota were infected with Mycobacteria and that M. Avium was the predominant species. It becomes evident the need to improve the preventive measures and prompt treatment of this type of opportunistic infection in the HIV infected individuals.

\section{Competing interests}

None declared

\section{Acknowledgement}

This work was financed by the Ministry of Health of Colombia, contract 809I54, and by DIB (Universidad Nacional de Colombia), grant 701-98.

\section{References}

1. Center for Disease Control and Prevention: Transmission of multidrug-resistant tuberculosis from an HIV-positive client in a residential substance-abuse treatment facility-Michigan. MMWR Morb Mortal Wkly Rep I991, 40:129-I31

2. Center for Disease Control and Prevention: Nosocomial transmission of multidrug-resistant tuberculosis among HIV-infected persons-Florida and New York, 1988-1991. MMWR Morb Mortal Wkly Rep 1991, 40:585-59|

3. Daley CL, Small PM, Schecter GF, Schoolnik GK, McAdam RA, Jacobs WR, Hopewell PC: An outbreak of tuberculosis with accelerated progression among persons infected with the human immunodeficiency virus. An analysis using restrictionfragment-length polymorphisms. N Engl J Med 1992, 326:23I235

4. Edlin BR, Tokars JI, Grieco MH, Crawford JT, Williams J, Sordillo EM, KR Ong, Kilburn JO, Dooley SW, Castro KG, et al: An outbreak of multidrug-resistant tuberculosis among hospitalized patients with the acquired immunodeficiency syndrome. $N \mathrm{Engl}$ J Med 1992, 326: I5|4-152|

5. Victoria JE: Epidemiologia de la tuberculosis en Colombia. Informe Quincenal Epidemiológico Nacional 1999, 4:82-85

6. Allen S, Batungwanayo J, Kerlikowske K, Lifson AR, Wolf W, Granich R, Taelman H, Van de Perre P, Serufilira A, Bogaerts ] ], et al: Twoyear incidence of tuberculosis in cohorts of HIV-infected and uninfected urban Rwandan women. Am Rev Respir Dis 1992, | 46: |439- | 444

7. Selwyn PA, Sckell BM, Alcabes P, Friedland GH, Klein RS, Schoenbaum EE: High risk of active tuberculosis in HIV-infected drug users with cutaneous anergy. JAMA 1992, 268:504-509

8. Guelar A, Gatell JM, Verdejo J, Podzamczer D, Lozano L, Aznar E, Miro JM, Mallolas J, Zamora L, Gonzalez J, et al: A prospective study of the risk of tuberculosis among HIV-infected patients. AIDS 1993, 7:1345-139

9. Moreno S S, Baraia-Etxaburo J, Bouza E, Parras F, Perez-Tascon M, Miralles $P$, et al: Risk for developing tuberculosis among anergic patients infected with HIV. Ann Intern Med I 993, I I 9:194- 198

10. Pape JW, Jean SS, Ho JL, Hafner A, Johnson WD: Effect of isoniazid prophylaxis on incidence of active tuberculosis and progression of HIV infection. Lancet 1993, 342:268-272

II. Melnick SL, Sherer R, Louis TA, Hillman D, Rodriguez EM, Lackman C, Capps L, Brown LS, Carlyn M, Korvick JA, et al: Survival and disease progression according to gender of patients with HIV infection. The Terry Beirn Community Programs for Clinical Research on AIDS. JAMA 1994, 272:1915-1921

12. Graham NM, Cohn S, Galai N, Astemborski J, Nelson KE, Vlahov D: Incidence of mycobacterial infection and disease in $\mathrm{HIV}+$ and HIV- IDUs [Abstract]. Int Conf AIDS 1993, 9:328

13. Antonucci G, Girardi E, Raviglione MC, Ippolito G: Risk factors for tuberculosis in HIV-infected persons. A prospective cohort study. The Gruppo Italiano di Studio Tubercolosi e AIDS (GISTA). JAMA 1995, 274:143-148

14. Dupon M, Texier-Maugein J, Leroy V, Sentilhes A, Pellegrin JL, Morlat $P$, et al: Tuberculosis and HIV infection: a cohort study of incidence and susceptibility to antituberculous drugs, Bor- deaux, 1985-1993. Groupe d'Epidemiologie Clinique du SIDA en Aquitaine. AIDS 1995, 9:577-583

15. Horsburgh CR: Mycobacterium avium-complex infection in the acquired immunodeficiency syndrome. N Engl] Med I99|, 324:1332-1338

16. Hoover DR, Saah AJ, Bacellar H, Phair J, Detels R, Anderson R, et al: Clinical manifestations of AIDS in the era of Pneumocystis prophylaxis. N Engl J Med 1993, 329:1922-1926

17. Chaisson RE, Moore RD, Richman DD, Keruly J, Creagh T: Incidence and natural history of Mycobacterium aviu m-complex infections in patients with advanced HIV disease treated with zidovudine. The Zidovudine Epidemiology Study Group. Am Rev Respir Dis 1992, 146:285-289

18. Nightingale SD, Byrd LT, Southern PM, Jockusch JD, Cal SX, Wynne BA: Incidence of Mycobacterium avium - intracellulare complex bacteremia in human immunodeficiency virus-positive patients. J Infect Dis 1992, 165:1082-1085

19. Horsburgh CR, Havlik JA, Ellis DA, Kennedy E, Fann SA, Dubois RE, Thompson SE: Survival of patients with acquired immune deficiency syndrome and disseminated Mycobacterium avium complex infection with and without antimycobacterial chemotherapy. Am Rev Respir Dis 1991, 144:557-559

20. Jacobson MA, Hopewell PC, Yajko DM, Hadley WK, Lazarus E, Mohanty PK, GW Modin, Feigal DW, Cusick PS, Sande MA: Natural history of disseminated Mycobacterium avium complex infection in AIDS. J Infect Dis 1991, 164:994-998

21. Instituto Nacional de Salud: Tuberculosis, Manual de Procedimientos Bogota 1990

22. Center for Diseases Control: Mycobacteriology, A guide for the level III laboratory Atlanta 1985

23. Rothman KJ: Modern Epidemiology. Boston: Little, Brown 1986 , 155, 172:196-213

24. Kahn HA, Sempos CT: Statistical Methods in Epidemiology New York: Oxford Univ Pr 1989219

25. Murcia M, León $\mathrm{Cl}$, de la Hoz F, Saravia J: Frecuencia de las infecciones micobacterianas en pacientes VIH positivos que acuden a las consultas del Hospital san Juan de Dios. Biomedica 1996, 16(suppI I):23

26. Crespo MP, Corral R, Alzate A: El diagnostico de la infección por micobacterias en individuos $\mathrm{VIH}$ positivos. Colombia Medica |994, 25:86-9|

27. Conde MB, Figueira CM, Moraes R, Fonseca LS, Deriemer K, Kritski $A L$ : Predictive value of the acid fast smear for detection of Mycobacterium tuberculosis in respiratory specimens in a reference center of HIVIAIDS in Rio de Janeiro, Brazil. Mem Inst Oswaldo Cruz 1999, 94:787-790

28. Horsburgh CR: Epidemiology of mycobacterial diseases in AIDS. Res Microbiol I 992, 143:372-377

29. Coker RJ, Hellyer TJ, Brown IN, Weber JN: Clinical aspects of mycobacterial infections in HIV infection. Res Microbiol 1992, |43:377-38|

30. Gómez Marin JE, Rigouts L, Villegas Londoño LE, Portaels F: Restriction Fragment Length Polymorphism (RFLP) analysis and tuberculosis epidemiology. Bull PAHO 1995, 29:226-236

Publish with BioMed Central and every scientist can read your work free of charge

"BioMedcentral will be the most significant development for disseminating the results of biomedical research in our lifetime." Paul Nurse, Director-General, Imperial Cancer Research Fund

Publish with BMC and your research papers will be:

- available free of charge to the entire biomedical community

- peer reviewed and published immediately upon acceptance

- cited in PubMed and archived on PubMed Central

- yours - you keep the copyright

Submit your manuscript here:

http://www.biomedcentral.com/manuscript/ 